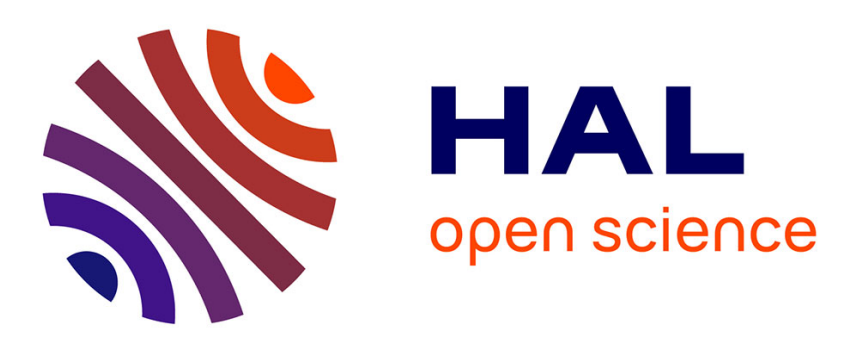

\title{
Resisting classical solutions: The creative mind of industrial designers and engineers.
}

Marine Agogué, Pascal Le Masson, Cédric Dalmasso, Olivier Houdé, Mathieu

Cassotti

\section{- To cite this version:}

Marine Agogué, Pascal Le Masson, Cédric Dalmasso, Olivier Houdé, Mathieu Cassotti. Resisting classical solutions: The creative mind of industrial designers and engineers.. Psychology of Aesthetics, Creativity, and the Arts, 2015, pp.10.1037/a0039414. 10.1037/a0039414 . hal-01199938

\section{HAL Id: hal-01199938 \\ https://hal-mines-paristech.archives-ouvertes.fr/hal-01199938}

Submitted on 16 Sep 2015

HAL is a multi-disciplinary open access archive for the deposit and dissemination of scientific research documents, whether they are published or not. The documents may come from teaching and research institutions in France or abroad, or from public or private research centers.
L'archive ouverte pluridisciplinaire HAL, est destinée au dépôt et à la diffusion de documents scientifiques de niveau recherche, publiés ou non, émanant des établissements d'enseignement et de recherche français ou étrangers, des laboratoires publics ou privés. 
Resisting classical solutions:

The creative mind of industrial designers and engineers

\author{
Marine Agogué \\ HEC Montréal, Canada \\ Pascal Le Masson and Cédric Dalmasso, \\ Centre de Gestion Scientifique, Mines ParisTech, France
}

Olivier Houdé and Mathieu Cassotti

CNRS Unit 8340, Laboratory for the Psychology of Child Development and Education, Paris

Descartes University, France

Institut Universitaire de France

Corresponding author:

Marine Agogué

HEC Montréal

Département du Management

3000 chemin de la Côte Ste Catherine

H3T 2A7 Montréal, QC, Canada 


\begin{abstract}
Industrial designers and engineers are two types of individuals who are typically contrasted with regard to their creative capabilities. Regarding idea generation processes, studies have shown that individuals use existing elements to generate new ideas, which constrains theircreative thinking and leads them to only focus on a narrow scope of solutions. This article explores how industrial designers and engineers behave when generating creative ideas and resisting fixation (i.e., the propensity to focus on a limited set of ideas). We used a creative task in which participants were asked to design a solution that would prevent a hen's egg from breaking after being dropped from a height of $10 \mathrm{~m}$. Our results show that engineers and industrial designers differ in their creative behaviors when they are asked to generate ideas in a creative task, without any constraints. Industrial designers provide more answers and are less fixated than engineers. However, for both engineers and industrial designers, the introduction of an uncreative example reinforced the fixation effect and constrained the participants' fluency. Specifically, industrial designers who were exposed to an uncreative example behaved similarly to engineers who were not exposed to this type of example.
\end{abstract}

Keywords: creativity, fixation effect, design behavior, industrial designer, engineer 
Resisting classical solutions:

The creative mind of industrial designers and engineers

Creativity is a cognitive skill that is highly desired in a variety of situations and settings and can develop in different forms. Typically, contemporary societal stakes require decision-making reasoning and creative reasoning for people to generate new options, think of new possibilities and design new futures. Thus, creativity is a keyprocess in both science and the arts (Weisberg, 2006), and the discussion on the relationship between creativity in science and the arts is still growing. It, indeed,is core to the debate of creativity as being either a general or domain-specific capacity (Silvia, Kaufman,\& Pretz, 2009). Since the assumption of Snow (1959), which asserted that although scientists and artists evolve in different spheres, these types of individuals share intellectual traits, many studies have enriched the debate. Certain studies argued that students in the arts score significantly higher than do science students on divergent thinking tasks (Hartley \& Greggs, 1997), whereas more recent research underlined that there is no difference in the creative problem solving skills of students in the arts and science students (Williamson, 2011). Building more specifically on the perceptions of individuals regarding their own creativity, Charyton and Snelbeker (2007) focused on comparing how engineers and musicians identify either scientific or artistic creativity attributes. When asked to select adjectives that describe themselves, engineers tend to perceive themselves as individualistic and resourceful, whereas musicians consider themselves to have wide interests and to be insightful (ibid). Discussing creativity in the sciences or in the arts then relates to distinguishing individuals based on either their intrinsic capabilities or the nature of the creative activities in which these individualsbecomeinvolved. In addition, as stated by Silvia, Kaufman and Pretz (2009), arguing about whether creativity is specific or general usually depends on the methods that were used to investigatewhether focusing on creative output usually highlights domain-specific aspects of creativity 
andwhether focusing on creative traits tends to underscore general traits of creativity. Indeed, tasks vary in the reactions they generate in participants (Reiter-Palmon et al, 2009).

The debate on creativity in the sciences and the arts is echoed in current debates on the role of engineers and designers in the design of new products or new services. This stream of research has primarily emerged over the last decade because the activities of both professions have become more specified (Cross, 2001; Margolin, 2009; Valtonene, 2009). Industrial designers and engineers are,indeed,two types of individuals who are often asked to create innovative objects by going beyond the known solutions and proposing original designs (Yilmas, Daly, Seifert, \& Gonzalez, 2011; Ekvall, 2000; Court, 1998). However, they are typically contrasted with regard to their abilities to generate creative ideas (Daly, Yilmaz, Christian, Seifert, \& Gonzalez, 2012; Yilmaz \&Seifert, 2011); industrial designers are often considered to be biased towards the visual attributes, whereas engineers focus on performance (Wallace \& Jilkenia, 1993). Thus, engineers would rather express performance creativity in the sciences, whereas industrial designers would be more rooted in artistic creativity. Engineers rely on scientific discoveriesthat are based on a mix of algorithmic and associative thinking (Hayes, 1989) and have access to important material and human resources (Hatchuel, 2006), which displays a creative capability that is anchored in science. Conversely, industrial designers rely on mental representations (Bonnardel \& Marmèche, 2005), seek originality and use their artistic skills (Hakatie \& Ryynänen, 2007; Verganti, 2008) because they are asked to produce unknown objects that attract and surprise while still being understandable to novice observers (Tovey, 1998; Myerson, 2004). Indeed, industrial designers have to display generativeness (i.e., the ability to produce design proposals that differ from existing solutions and design standards; Arrighi, Le Masson \& Weil, in press).Moreover, recent studies have provided evidence that design students perform better on the Torrance Tests of Creative Thinking and are better able to control automatic processes (Edl et al., 2014). Therefore, 
comparing engineers and industrial designers enables us to identify refined mechanisms in creative thinking because both populations have to formulate novel solutions and use different processes to do so. As stated by Glaveanu and colleagues (2014), when facing a design situation, designers may rely on creating and solving, whereas engineers may use curiosity to explore new solutions. Thus, investigating the creative capacities of these two types of individuals who are often asked to perform similar tasks while having different perspectivesmay provide new insights for the debate on the domain generality or domain specificity ofcreativity.

To our knowledge, no work has been conducted that provides a specific comparison of the creative capacities of industrial designers and engineers, namely their ability to generate original and creative ideas. Differences in such creative capacities may not be the result of education; these differences may be grounded in personal preferences that would push an individual to undertake either engineering studies or designer studies. Therefore, studying the creativity of engineers and industrial designers cannot provide insight into the elements of education. However, engineering students are taught to find solutions to problems, reuse existing solutions and rely on existing models (Felder \& Silvermann, 1988; Perennet, Bouhuijs,\& Smits, 2000), whereas industrial design training is typically considered out-ofthe-box thinking (Driver, Peralta,\& Moultrie, 2011).

With regard to the phenomenon of idea generation processes, recent studies have shown that individuals tend to generate ideas that are based on cognitive routines (Smith, Ward,\& Schumacher, 1993; Agogué et al., 2014) and take the path of least resistance (Ward, Patterson,\& Sifornis, 2004). According to these studies, individuals use existing elements to generate new ideas, which constrains their creative thinking. Recent research has examined cognitive fixation during idea generation to shed light on the obstacles that people encounter during creative situations (Abraham \& Windmann, 2007; Jansson \& Smith, 1991; Smith, 
Ward, \& Finke, 1995; Smith, Ward, \& Schumacher, 1993). The fixation effect is characterized as a spontaneously activated type of reasoning that occurs during creative tasks and constrains further exploration (Purcell \& Gero, 1996). As an example, building upon the seminal task that was developed by Smith, Ward and Schumacher (1993), Abraham and Windmann (2007) asked participants to imagine and draw an animal that lives on another planet and is very different from existing animals on Earth. The authors sought to determine how the design of each animal that was drawn deviates from terrestrial animals and measured whether the proposals contained fundamental characteristics of animals, such as bilateral symmetry, the presence of members (e.g., legs or wings), and the presence of the sensory organs (e.g., eyes and ears). This study showed how individuals rely on their knowledge of existing terrestrial animals to create a new animal, which considerably limits the creative process. This tendency to use generic attributes of terrestrial animals is very strong, although the participants were explicitly asked not to do this.

Pursing the impact of an uncreative example on creative production, Agogué and colleagues (2013) demonstrated that the ability of under-graduates in psychology to generate new ideas can be constrained by exposure to uncreative examples. During the "task of the egg," in which subjects were asked to design solutions to prevent a hen's egg from breaking after being dropped from a height of 10 meters, the authors examined whetherthe introduction of an uncreative example (e.g., the use of a parachute to slow the fall) caused participants to reduce the number of solutions that were produced and the originality of their solutions. As previously stated, industrial designers should have experienced an increase in flexibility when generating novel ideas compared with engineers. However, the capabilities of engineers and industrial designers regarding fixation have not yet been studied.

Bridging these differing perspectives, the primary research question that isaddressed in this paper is the following: How do industrial designers and engineers behave when 
generating creative ideas and resisting fixation? Based on Agogué et al.'s (2013) research, we utilized the creative "egg" task to conduct an experiment that examined the creative capabilities of industrial designers and engineers. Herein, we plan to compare the creative capabilities of these two types of individuals by investigating their ability to generate ideas during this task, and we will analyze the possible constraining effect of exposure to a very classical, uncreative example. Based on the previously discussed studies, we hypothesize that industrial designers should outperform engineers, with regard to their ability to generate novel ideas. Moreover, regarding the constraining impact of exposure to an uncreative example, we hypothesize, extending the results of the study by Agogué et al. (2013) that was conducted with under-graduates in psychology, that engineers will be limited in their creative capability when exposed to this type of example. In contrast, one of the following two possible outcomes are likely for the industrial designers: they will either be hindered by an uncreative example, or their creative capabilities will allow them to be unaffected by a brief that includes an example of a solution that is within the fixation scope.

\section{Participants}

\section{Method}

Thirty-nine master's degree students in engineering from two engineering master's programs in Paris and thirty-three master's students in industrial design from a design school in Paris were recruited for this study. Participants were between 20 and 26 years old (mean age: 22.5 years), and $60 \%$ were male. Each participant was randomly assigned to one of the following two experimental conditions: a control group with no example $\left(\mathrm{N}_{\text {engineer }}=19,12\right.$ males, mean age: $21.9, \mathrm{SD}=1.33$ and $\mathrm{N}_{\text {designer }}=16,8$ males, mean age: $23, \mathrm{SD}=1.59$ ) ora group that was exposed to a very classic example $\left(\mathrm{N}_{\text {engineer }}=20,10\right.$ males, mean age: 22.6 , SD $=1.24$ and $\mathrm{N}_{\text {designer }}=17,13$ males, mean age: $23.1, \mathrm{SD}=1.22$ ). All of the participants were naive regarding the experimental aims, and none had experience with this specific task. 


\section{Procedure}

Instructions for the task were provided on a sheet of paper, and the experiment occurred at the beginning of a lecture on innovation management. Participants were asked to make a list of creative solutions and were forbidden from talking to one another for the duration of the task. Participants were randomly assigned to one of two experimental conditions (i.e., control group without example and group with uncreative example) and were given ten minutes to generate as many original solutions as they could to one of the following problems:

\section{Control group: Without example}

"You are a designer, and you are asked to propose as many original solutions as possible to the following problem: Ensure that a hen's egg that is dropped from a height of $10 \mathrm{~m}$ does not break."

\section{Group with example: Exposed to an uncreative example}

"You are a designer, and you are asked to propose as many original solutions as possible to the following problem: Ensure that a hen's egg that is dropped from a height of $10 \mathrm{~m}$ does not break. The most frequently proposed solution is to slow the fall with a parachute."

The task was administered silently and individually, and participants had to write down their solutions by using short sentences.

\section{Data Analysis}

The performance of the engineers and industrial designers on the egg task was quantified by means of a fluency score (i.e., the capacity to generate numerous solutions) and an originality score (i.e., the quality of the produced ideas,; Fink et al., 2010). We further

\footnotetext{
${ }^{1}$ The instructions were written in French, and the neutral term «concepteur » was used as a translation of « designer », priming no identity effects on neither engineers nor industrial designer.
} 
added a new measure of the creative outputs, which is referred to as expansivity (i.e., the capacity to generate numerous solutions that are outside of the fixation effect).

To measure fluency, we counted the number of solutions that were provided by the participants. When a participant proposed a solution that was a combination of different proposals, we counted each proposal as one solution.

To assess originality, we applied an external rating procedure that was similar to the consensual assessment technique that was proposed by Amabile (1982). More specifically, two independent raters were instructed to evaluate each idea on a five-point rating scale, ranging from 1 ("not original at all") to 5 ("highly original"). The raters displayed a satisfactory intra-class correlation coefficient $(\mathrm{ICC}=.89)$. Each participant was then scored on the mean rating of the originality scores of all of the solutions as in (Fink et al. 2012; Kleibeuker et al. 2013).

We further computed a new measurement, expansivity, by studying the distribution of the solutions among the different categories. We characterized expansivity as the number of solutions that were outside the fixation effect. To do this, two trained raters assigned each solution that was given by the participants to one of 10 meta-categories. Inter-rater agreement was excellent (percent agreement $=97 \%$ ). Based on a previous study (Agogué et al., 2013; 2014), three meta-categories (i.e., dampening the shock, protecting the egg, and slowing the fall) met the qualifications for the fixation effect, whereas the seven others did not (e.g., using a living device and modifying the natural properties of the egg). We then counted the number of solutions that were outside the fixation effect for each participant.

Kolmogorov-Smirnov tests regarding the fluency, originality and expansivity scores confirmed the normality of the distributions (all $\mathrm{p}$ values $>.15$ ). Therefore, to determine whether exposure to an uncreative example impacted the fluency, originality and expansivity scores of industrial designers and engineers, we conducted two-way analyses of variance 
(ANOVAs), with educational training (industrial designers vs. engineers) and experimental groups (control group vs. group with example) as the between-subjects factors.

\section{Results}

\section{Fluency}

Regarding the number of solutions that were provided by each participant (see Figure 1A), the ANOVA revealed a main effect of educational training, $\mathrm{F}(1,68)=10.63, \mathrm{p}=.002$, $\eta_{p}{ }^{2}=.14$, which showed that industrial designers provided more solutions, $\mathrm{M}=7.12, \mathrm{SD}=$ 2.72, than engineers, $\mathrm{M}=5.44, \mathrm{SD}=2.16$. This analysis also revealed a main effect of experimental group, $\mathrm{F}(1,68)=12.78, \mathrm{p}=.0006, \eta_{p}{ }^{2}=.16$, which indicates that the participants were impacted by the exposure to the uncreative example. Critically, engineers and industrial designers provided fewer solutions after being exposed to an example, $\mathrm{M}=$ $5.31, \mathrm{SD}=2.28$, compared with the control groups, $\mathrm{M}=7.11, \mathrm{SD}=2.54$ (see table 2).However, there was no significant interaction between educational training and experimental group, $\mathrm{F}(1,68)=1.47, \mathrm{p}=.22, \eta_{p}{ }^{2}=.02$.

Insert Figure1 about here

\section{Originality}

With regard to mean originality (see Figure 1B), the ANOVA revealed a main effect of educational training, $\mathrm{F}(1,68)=8.69, \mathrm{p}=.004, \eta_{p}{ }^{2}=.11$, which indicates that the solutions given by designers are more original, $\mathrm{M}=2.08, \mathrm{SD}=0.55$, than those provided by engineers, $\mathrm{M}=1.75, \mathrm{SD}=0.49$. There was also a main effect of experimental group, $\mathrm{F}(1,68)=10.56, \mathrm{p}$ $=.002, \eta_{p}{ }^{2}=.13$, which shows that the solutions proposed by the participants in the group 
that wasexposed to the example are less original, $\mathrm{M}=1.72, \mathrm{SD}=0.5$, than thosegiven by the participants in the control groups, $\mathrm{M}=2.09, \mathrm{SD}=0.53$. There was no significant interaction between educational training and experimental group, $\mathrm{F}(1,68)=0.004, \mathrm{p}=.95, \eta_{p}{ }^{2}=.0005$ (see table 2).

Furthermore, we tested the link between originality and fluency on the entire sample for the independence of the two measures. We found a weak positive correlation between originality and fluency $(\mathrm{r}=.31, \mathrm{p}=.007)$ (see table 1; Dancey, \& Reidy, 2004).

Insert table 1 about here

\section{Expansivity}

With regard to expansivity (i.e., the number of solutions that are outside the fixation effect; Figure 2), the ANOVA revealed a main effect of educational training, $F(1,68)=13.68$, $\mathrm{p}=.0004, \eta_{p}{ }^{2}=.17$, which shows that industrial designers provided more solutions that were outside the fixation effect, $\mathrm{M}=2.33, \mathrm{SD}=1.89$, than did engineers, $\mathrm{M}=0.97, \mathrm{SD}=1.22$. This analysis also revealed a main effect of experimental group, $F(1,68)=16.68, p=.0001$, $\eta_{p}{ }^{2}=.26$, which indicates that the number of solutions that are outside the fixation effect was lower after exposure to the uncreative example, $\mathrm{M}=1, \mathrm{SD}=1.33$, compared with the control groups, $\mathrm{M}=2.19, \mathrm{SD}=1.83$ (see table 2). However, there was no significant interaction between educational training and experimental group, $\mathrm{F}(1,68)=1.31, \mathrm{p}=.26, \eta_{p}{ }^{2}=.02$.

Critically we found a significant correlation between originality and expansivity $(\mathrm{r}=$ $.74, \mathrm{p}<. .0001)$ 
Insert table2 about here

\section{Discussion}

The present experiment compared the creative capabilities of engineers and industrial designers in a situation that required them to move away from obvious classical solutions (i.e., a situation in which individuals had to overcome a design fixation). We used a creative task in which participants were asked to design a solution that would prevent a hen's egg from breaking after being dropped from a height of $10 \mathrm{~m}$. This task allowed us to compare the individuals' abilities to activate different types of reasoning to explore original solutions, based on their education.

Two major findings emerged from this investigation. First, we confirmed that the participants' ability to generate creative ideas depended on their backgrounds. Our results suggest that engineers and industrial designers differ in their creative behaviors when they are asked to generate ideas. Industrial designers performed better than engineers with regard to fluency and were less fixated, which are qualities that are frequently associated with their field (Verganti, 2009; Yilmaz, Seifert, \& Gonzalez, 2011). Specifically, the significant correlation between originality and expansivity showed that the solutions that are outside the fixation are the most original according to expert judgment and therefore the more expansive the solutions are, the more original they are as well.. It is a validation of the model proposed in (Agogué et al, 2014) and therefore to propose original solutions, individuals need to overcome fixation effects. Second, for both the engineers and industrial designers, the introduction of an uncreative example reinforced the fixation effect and constrained both their fluency and their expansivity. Thus, our results are consistent with those of Agogué et al. (2013), which showed that an uncreative example that was chosen within the fixation effect 
constrains the creative capabilities of individuals. Of particular interest in the present study is that the industrial designers who were exposed to a restrictive example behaved similarly to the engineers in the control group. Therefore, the creative capacity of designers is limited by the instructions that are provided to them when an uncreative example is included. In other words, industrials designers show a certain degree of a fixation effect, similar to everyone else, regardless of their reputation to be able to overcome fixation.

Our results call the managerial approach of involving engineers and designers in creative settings into question (Amabile, 1996). Our findings suggest that both engineers and industrial designers can be influenced by an uncreative example of a solution when this example is given by another person (in the case of our protocol, the example is given by the experimenter). If we may conduct an analogy that uses a real-life creative setting, a manager that focuses on the generation of new and creative ideas should be aware that when giving a creative task to an individual, the manner in which he/she frames the briefs may have an impact on that person's performance during the ideation process, and a classical solution may hinder creative production (in terms of the number of ideas and in terms of the quality of the produced ideas). Industrial designers are often praised for their creative capabilities, which our results support, yet managers of industrial designers should be careful because the designers' expansivity (i.e., their ability to conduct out-of-the-box reasoning) can be constrained by exposure to examples.

The conclusions that we can draw from studying the creative abilities of engineers and designers are not without limitation. If design and engineering educations differ, our results can shed light on the abilities of specific individuals who chose certain training programs, butno conclusion can be made regarding only their education. Indeed, engineers and designers may have different creative capabilities, thoughthis may be due to their choice of a specific carrier path or even their natural abilities that incite them to pursue a certain education, rather 
than the education itself. Conducting research on the impact of engineering and design education should include a longitudinal study and focus on a dynamic baseline of the creative abilities of engineers-to-be and designers-to-be.

Future research is necessary, based on the present results. First, we only compared one aspect of creative cognition in engineers and industrial designers, namely their capacity to resist design fixation and how this ability is influenced by exposure to a classical example of a solution. Other aspects of idea generation phases should be explored, and future studies should analyze other types of examples (Agogué et al., 2013; Fink et al., 2010) and the impact of providing several examples simultaneously (Dugosh \& Paulus, 2005). Second, this study should be extended to other types of individuals. Finally, experiments examining the creative cognition in cooperative protocols regarding engineers and industrial designers would shed light on the influence of cooperation on design fixation. 


\section{References}

Abraham, A., \& Windmann, S. (2007). Creative cognition: The diverse operations and the prospect of applying a cognitive neuroscience perspective,Methods, 42, 38-48.

Agogué M., Kazakçi A.O., Hatchuel A., Le Masson P., Weil B., Poirel N., Cassotti M., (2013). The impacts of examples on originality: explaining fixation and stimulation effects, TheJournal of Creative Behavior, 48, 1-12.

Agogué M., Poirel N., Pineau A., Houdé O., Cassotti M., (2014). The impact of age and training on creativity: a design-theory approach to study fixation effects, Thinking Skills and Creativity, 11, 33-41.

Amabile, T., (1982). Social psychology of creativity: a consensual assessment technique. Journal of Personality and Social Psychology,43, 997-1013.

Amabile, T.M. (1996). Creativity and innovation in organizations (Vol. 5). Boston: Harvard Business School.

Arrighi, P-A., Le Masson P., \& Weil B. (in press) Addressing constraints creatively; how ne design software helps solve the dilemma of originality and feasibility, Creativity and Innovation Management.

Bonnardel, N., \& Marmèche, E. (2005). Towards supporting evocation processes in creative design: A cognitive approach. International Journal of Human-Computer Studies, 63(4), 422-435.

Charyton, C., \& Snelbecker, G.E. (2007). Engineers' and musicians' choices of selfdescriptive adjectives as potential indicators of creativity by gender and domain,Psychology of Aesthetics, Creativity, and the Arts, 1, 91-99.

Court, A.W. (1998). Improving creativity in engineering design education. European Journal of Engineering Education, 23, 141-154.

Cross, N. (2001). Designerly ways of knowing: design discipline versus design science. Design issues, 17, 49-55.

Daly, S.R., Yilmaz, S., Christian, J.L., Seifert, C.M., \& Gonzalez, R. (2012). Design heuristics in engineering concept generation. Journal of Engineering Education, 101, $601-629$.

Dancey, C., \& Reidy, J. (2004). Statistics without Maths for Psychology: using SPSS for Windows, London: Prentice Hall.

Driver, A. J., Peralta, C., \& Moultrie, J. (2011). Exploring how industrial designers can contribute to scientific research. International Journal of Design, 5(1), 17-28.

Dugosh, K.L., \& Paulus, P.B. (2005). Cognitive and social comparison processes in brainstorming. Journal of Experimental Social Psychology, 41, 313-320. 
Edl, S., Benedek, M., Papousek, I., Weiss, E. M., \& Fink, A. (2014). Creativity and the Stroop interference effect. Personality and Individual Differences, 69, 38-42.

Ekvall, G. (2000). Management and organizational philosophies and practices as stimulants or blocks to creative behavior: a study of engineers. Creativity and Innovation Management, 9(2), 94-99.

Felder, R.M., \& Silverman, L.K. (1988). Learning and teaching styles in engineering education.Engineering education, 78, 674-681.

Fink, A., Grabner, R.G., Gebauer, D., Reishofer, G., Koschutnig K., \& Ebner F. (2010). Enhancing creativity by means of cognitive stimulation: Evidence from an fMRI study. NeuroImage, 52, 1687-1695.

Fink, A., Koschutnig, K., Benedek, M., Reishofer, G., Ischebeck, A., Weiss, E. M., \& Ebner, F. (2012). Stimulating creativity via the exposure to other people's ideas. Human brain mapping, 33(11), 2603-2610.

Glaveanu, V., Lubart, T., Bonnardel, N., Botella, M., de Biaisi, P. M., Desainte-Catherine, M., ... \& Zenasni, F. (2013). Creativity as action: findings from five creative domains. Frontiers in psychology, 4.

Hakatie, A., \& Ryynänen, T. (2007). Managing creativity: a gap analysis approach to identifying challenges for industrial design consultancy services. Design Issues, 23, 28 46.

Hartley, J., \& Greggs, M. A. (1997). Divergent thinking in arts and science students: Contrary Imaginations at Keele revisited. Studies in Higher Education, 22, 93-97.

Hatchuel, A. (2006). Quelle analytique de la conception? Parure et pointe en design. In Flamant, B. (Eds), Le design. Theories et pratiques. Paris: IFM Editions.

Hayes, J. R. (1989). Cognitive processes in creativity (pp. 135-145). Springer US.

Jansson, D., \& Smith, S. M. (1991). Design Fixation. Design Studies, 12, 3-11.

Kleibeuker, S.W., Koolschijn, P.C.M.P., Jolles, D.D., Schel, M.A. de Dreu, C.K.W. \& Crone, E.A. (2013). Prefrontal cortex involvement in creative problem solving in middle adolescence and adulthood. Developmental Cognitive Neuroscience, 5, 197-206.

Margolin V., (2009), Design in History, Design Issues, 25, 94-105.

Myerson, J. (2004). IDEO: Masters of innovation. Laurence King.

Perrenet, J.C., Bouhuijs, P.A.J., \& Smits, J.G.M. (2000). The suitability of problem-based learning for engineering education: theory and practice. Teaching in higher education, 5 , $345-358$.

Purcell, T., \& Gero, J.S. (1996). Design and other types of fixation. Design Studies, 17, 363383. 
Reiter-Palmon, R., Illies, M. Y., Cross, L. K., Buboltz, C., \& Nimps, T. (2009). Creativity and domain specificity: The effect of task type on multiple indexes of creative problemsolving. Psychology of Aesthetics, Creativity, and the Arts, 3(2), 73.

Silvia, P.J., Kaufman, J.C., \& Pretz, J.E. (2009). Is creativity domain-specific? Latent class models of creative accomplishments and creative self-descriptions. Psychology of Aesthetics, Creativity, and the Arts, 3, 139-148.

Smith, S.M., Ward, T.B., \& Schumacher, J.S. (1993). Constraining effects of examples in a creative generation task.Memory and Cognition, 21, 837-845.

Smith, S.M., Ward, T., \& Finke, R.A. (1995). The creative cognition approach. Cambridge, MA, USA: The MIT Press.

Snow, C.P. (1959). The Rede lecture. In C.P. Snow (Ed.), The two cultures (pp. 1-51). Cambridge: Cambridge University Press.

Tovey, M. (1997). Styling and design: intuition and analysis in industrial design. Design Studies, 18, 5-31.

Valtonen, A. (2009). Six decades and six different roles for the industrial designer. Nordes, (1).

Verganti, R. (2008). Design, meanings and radical innovation: a meta-model and a research agenda. Journal of Product Innovation Management, 25, 436-456.

Verganti, R. (2009). Design-Driven Innovation: Changing the Rules of Competition by Radically Innovating What Things Mean.Boston: Harvard Business School Press.

Wallace, D. R., \& Jakiela, M. J. (1993). Automated product concept design: Unifying aesthetics and engineering. Computer Graphics and Applications, IEEE, 13(4), 66-75.

Ward, T., Patterson, M.J., \& Sifonis, C.M. (2004). The role of specificity and abstraction in creative idea generation. Creativity Research Journal, 16,1-9.

Weisberg, R. W. (2006). Creativity: Understanding innovation in problem solving, science, invention, and the arts. John Wiley \& Sons.

Williamson, P. K. (2011). The creative problem solving skills of arts and science students: the two cultures debate revisited. Thinking Skills and Creativity, 6, 31-43.

Yilmaz, S., \& Seifert, C.M. (2011). Creativity through design heuristics: a case study of expert product design. Design Studies, 32, 384-415.

Yilmaz, S., Daly, S.R., Seifert, C.M., \& Gonzalez, R. (2011). A comparison of cognitive heuristics use between engineers and industrial designers. In Gero, J. (Ed.). Design Computing and Cognition'10. Netherlands: Springer. 
Table 1

Inter-correlations between each dependent variable for the entire sample.

Originality Expansivity

\begin{tabular}{lccc}
\hline & Fluency & $.31^{*}$ & $.65^{* *}$ \\
Entire sample & Originality & & $.74^{* *}$ \\
& & & \\
\hline
\end{tabular}


Table 2

Means and standard deviations for fluency, originality and the number of solutions that are outside the fixation effect, as a function of educational training (industrial designers vs. engineers) and experimental groups (control group vs. group with example).

\begin{tabular}{|c|c|c|c|c|}
\hline & & Fluency & Originality & Expansivity \\
\hline \multirow{4}{*}{ Industrial designers } & Control & $8.44(2.31)$ & $2.28(0.5)$ & $3.19(1.87)$ \\
\hline & With example & $5.88(4.79)$ & $1.9(0.54)$ & $1.53(1.58)$ \\
\hline & Average & $7.12(2.72)$ & $2.08(0.55)$ & $2.33(1.89)$ \\
\hline & Control & $6.05(2.23)$ & $1.93(0.51)$ & $1.4(1.39)$ \\
\hline \multirow[t]{2}{*}{ Engineers } & With example & $4.79(1.93)$ & $1.56(0.41)$ & $0.53(0.84)$ \\
\hline & Average & $5.44(2.16)$ & $1.75(0.49)$ & $0.97(1.22)$ \\
\hline Entire sample & & $6.21(2.56)$ & $1.91(0.54)$ & $1.6(1.7)$ \\
\hline
\end{tabular}




\section{Control Group $\square$ Group with example}
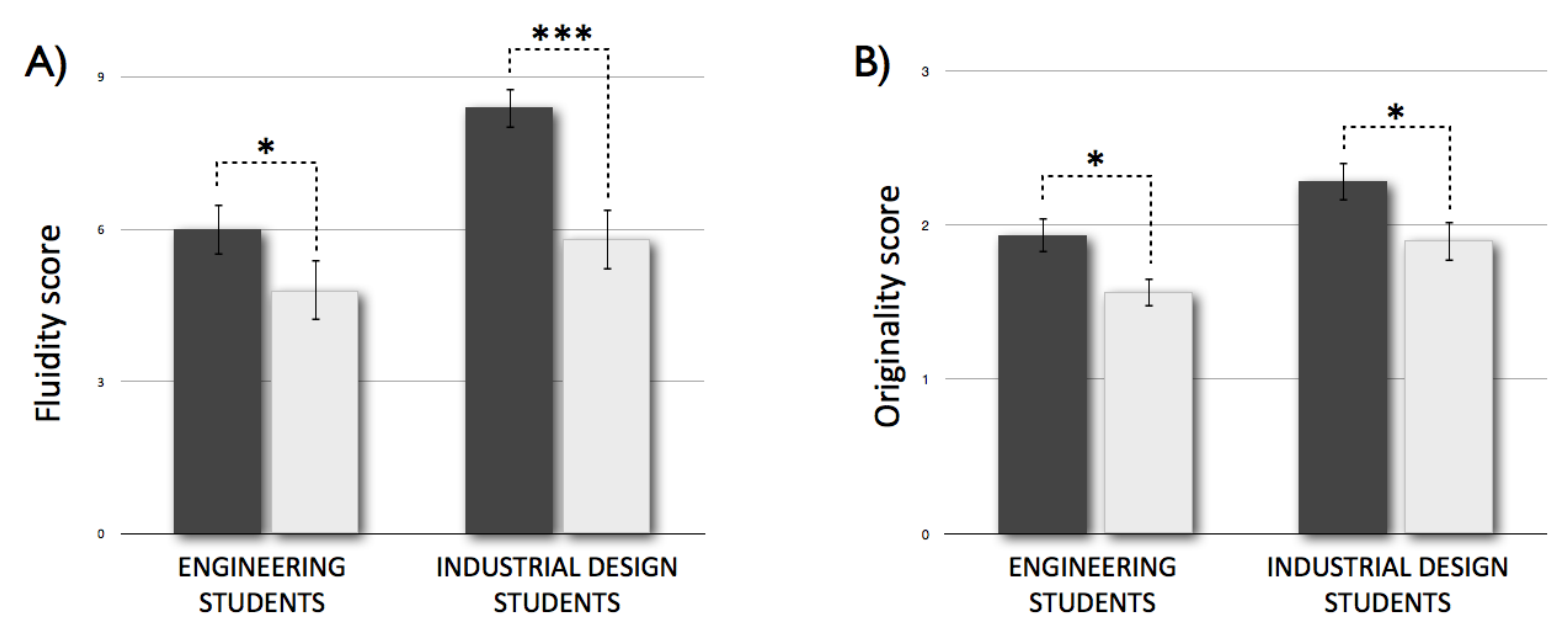

Figure 1. Impact of the exposure to an uncreative example on A) the fluency score and B) the originality score of industrial designers and engineers. $*: p<.05 ; * * *: p<.005$. 